\title{
Bargaining over perfect complements owned separately: With experimental test
}

\author{
Ning Yu ${ }^{\mathrm{a}, \mathrm{b}, *}$, Thorsten Chmura ${ }^{\mathrm{c}, \mathrm{d}}$, Thomas Pitz ${ }^{\mathrm{c}, \mathrm{d}}$, Ning Sun ${ }^{\mathrm{e}}$ \\ a School of Economics, Shanghai Jiao Tong University, 535 Fahuazhen Road, Shanghai, 200052, China \\ b Department of Economics, W. P. Carey School of Business, Arizona State University, University Drive and Mill Avenue, Tempe, AZ, 85287, USA \\ c Nottingham University Business School China, 199 Taikang East Road, Ningbo, 315100, China \\ ${ }^{d}$ University of Bonn, BonnEconLab - Laboratory of Experimental Economics, Adenauerallee 24-42, 53113 Bonn, Germany \\ e School of Economics, Shanghai University of Finance and Economics, 111 Wuchuan Road, Shanghai, 200433, China
}

\section{A R T I C L E I N F O}

\section{Article history:}

Received 30 June 2009

Received in revised form 26 November 2009

Accepted 17 December 2009

Available online 28 December 2009

\section{JEL classification:}

C78

$\mathrm{C} 92$

\section{Keywords:}

$k+1-$ price bargaining/auction

Perfect complements

Experimental economics

\begin{abstract}
A B S T R A C T
This paper considers the situation in which two perfect complements belong to different owners. We calculate the Bayesian-Nash equilibrium in the mechanism of $k+1$-price bargaining with private value, and did experiment to test the theory.
\end{abstract}

(C) 2009 Elsevier B.V. All rights reserved.

\section{Introduction}

Cramton et al. (1987) study a partnership dissolving under incomplete information using the tool of mechanism design. We consider a similar but distinct situation in which one piece of perfect complement is useless for its owner. For example, one consumer owns 3 out of 4 volumes of a dictionary, and another accidentally has the other 1 volume. We focus on the mechanism of $k+1$ - price auction or bargaining, probably first introduced by Chatterjee and Samuelson (1983), and adopt the notation of Cramton et al. (1987) in which $k \in[0,1]$, and $k=0$ and 1 represent the first-price and second-price sealed auctions respectively. We study the Bayesian-Nash equilibrium in this scenario, and test whether players follow the predicted bidding strategy in reality.

\section{The model}

We consider a 2-player $(i=1,2)$ asymmetric incomplete information game that the well-established framework of the Bayesian-Nash equilibrium is applicable. The signal $v_{i}$ of player $i$ distributes according to the cumulative distribution function (c.d.f.) $F_{i}(v)$ on the closed interval

\footnotetext{
* Corresponding author. Department of Economics, W. P. Carey School of Business, Arizona State University, University Drive and Mill Avenue, Tempe, AZ, 85287, USA Tel.: +1 480965 3531; fax: +1 4809650748 .

E-mail addresses: ningyu@asu.edu (N. Yu), chmura@uni-bonn.de (T. Chmura), tpitz@uni-bonn.de (T. Pitz), nsun@mail.shufe.edu.cn (N. Sun).
}

$\left[\underline{v}_{i}, \bar{v}_{i}\right]$, with a positive and twice continuously differentiable probability density function (p.d.f.) $f_{i}(v)$. These signals tell how much the players value the combination respectively. The distributions are common knowledge, but each one only receives her own signal. Player $i$ owns a share $\theta_{i} \geq 0$ of the combination, and $\theta_{1}+\theta_{2}=1$. By doing so, the sellerbuyer bargaining model becomes a degenerate case of ours. The ownership structure is clear or pre-agreed, and how it is obtained is not of our concern.

The mechanism determines the price of the combination of two perfect complements according to messages sent by two players, that is, $(1-k) b^{(1)}+k b^{(2)}$, where $b^{(i)}$ stands for the $i$-th higher message sent by them. The higher bidder $i$ gets the combination, and pays the other $\theta_{j}\left[(1-k) b^{(1)}+k b^{(2)}\right]$. In conclusion, for an arbitrary bidder $i$, the ex post payoff is given by

$\pi_{i}= \begin{cases}v_{i}-\theta_{j}\left[(1-k) b_{i}+k b_{j}\right] & \text { if } \quad b_{i}>b_{j}, \\ \frac{1}{2}\left(v_{i}-\theta_{j} b_{i}\right)+\frac{1}{2} \theta_{i} b_{i} & \text { if } \quad b_{i}=b_{j}, \\ \theta_{i}\left[(1-k) b_{j}+k b_{i}\right] & \text { if } \quad b_{i}<b_{j} .\end{cases}$

The equilibrium strategy consists of two bidding functions $\beta_{1}(v)$ and $\beta_{2}(v)$, guiding player $i$ to submit a message or bid of $b_{i}=\beta_{i}(v)$ when she receives a signal $v$. They satisfy

$$
\left\{\begin{array}{l}
\Pi_{1}\left(\beta_{1}(v), v\right) \geq \Pi_{1}(b, v) \text { for all } v \in\left[\underline{v}_{1}, \bar{v}_{1}\right] \text { and } b, \\
\Pi_{2}\left(\beta_{2}(v), v\right) \geq \Pi_{2}(b, v) \text { for all } v \in\left[\underline{v}_{2}, \bar{v}_{2}\right] \text { and } b,
\end{array}\right.
$$


where $\Pi_{i}\left(\beta_{i}(v), v\right)$ stands for the expected payoff given $\beta_{j}(v)$ and $F_{j}(v)$. With a bidding function, it is easy to compute the corresponding c.d.f. of the player's bid, and we set them to be $G_{1}(b)$ and $G_{2}(b)$.

We now characterize the properties of certain bidding functions in equilibrium and corresponding c.d.f. of bids in the form of assumptions because the proofs of them are standardized in the auction literature and apply here with marginal modifications. The representative ones can be found in Amann and Leininger (1996), Lizzeri and Persico (2000), and Maskin and Riley (2003).

Assumption 1. [Common extrema]

$\left\{\begin{array}{l}\inf \left(b_{1}\right)=\inf \left(b_{2}\right)=\underline{b}, \text { and } \\ \sup \left(b_{1}\right)=\sup \left(b_{2}\right)=\bar{b}\end{array}\right.$

Assumption 2. [Single atoms at extrema] If $\underline{p}_{i}=\operatorname{Prob}\left(b_{i}=\underline{b}\right)=G_{i}(\underline{b})$, and $\bar{p} i=\operatorname{Prob}\left(b_{i}=\bar{b}\right)=1-\lim _{b \rightarrow{ }_{b}}-G_{i}(b)$, for $i=1,2$, then

$$
\left\{\begin{array}{l}
\min \left\{\underline{p}_{1}, \underline{p}_{2}\right\}=0, \text { and } \\
\min \left\{\bar{p}_{1}, \bar{p}_{2}\right\}=0
\end{array}\right.
$$

Assumption 3. [No atoms in between] For $i=1,2, G_{i}(b)$ is continuously differentiable on $(\underline{b}, \bar{b})$.

Assumption 4. [Monotonicity] For $i=1,2, \beta_{i}(v) \geq \beta_{i}\left(v^{\prime}\right)$ if $v>v^{\prime}$.

We can imply from these assumptions that there exist $\underline{w}_{i}$ and $\bar{w}_{i}$ that satisfy $F_{i}\left(\underline{w}_{i}\right)=\mathrm{p}_{i}$ and $1-F_{i}\left(\bar{w}_{i}\right)=\bar{p}_{i}$. It is obvious that if $p_{i}=0$, then $\underline{w}_{i}=\underline{v}_{i}$, and that if $\bar{p}_{i}=0, \bar{w}_{i}=\bar{v}_{i}$. The first derivative of $\bar{G}_{i}(b)$ is $g_{i}(b)$, and we know $\int_{b}^{b} g_{i}(t) d t=G_{i}(b)-\underline{p}_{i}$. We can assume further that the monotonicity property of bidding functions holds strictly on $\left[\underline{w}_{i}\right.$, $\left.\bar{w}_{i}\right]$, and $\beta_{i}(v)$ is differentiable.

The next task is looking for this unique equilibrium. We first focus on the straightforward part. For $v_{i} \in\left[\underline{w}_{i}, \bar{w}_{i}\right]$, the bidding function is strictly increasing, so an inverse bidding function $\phi_{i}(b)$ exists. The expected payoff of player $i$ after she receives a signal $v$ and bids $b$ is

$$
\begin{aligned}
\Pi_{i}(b, v)= & \underline{p}_{j}\left\{v-\theta_{j}[(1-k) b+k \underline{b}]\right\}+\int_{\underline{b}}^{b}\left\{v-\theta_{j}[(1-k) b+k t]\right\} g_{j}(t) d t+ \\
& +\int_{b}^{\bar{b}} \theta_{i}[(1-k) t+k b] g_{j}(t) d t+\bar{p}_{j} \theta_{i}[(1-k) \bar{b}+k b] \Pi_{i}(b, v) \\
= & \left(1-\theta_{i}\right) k \int_{\underline{b}}^{b} G_{j}(t) d t-\theta_{i}(1-k) \int_{b}^{\bar{b}} G_{j}(t) d t+(v-b) G_{j}(b)+ \\
& +\theta_{i} k b+\theta_{i}(1-k) \bar{b},
\end{aligned}
$$

where

$G_{j}(b)=\bar{p}_{j}+\int_{\underline{b}}^{b} g_{j}(t) d t=F_{j}\left(\phi_{j(b)}\right)$,

and

$g_{j}(b)=f_{j}\left(\phi_{j(b)}\right) \phi_{j}^{\prime}(b)$.

The first order condition is then

$\frac{\partial \Pi_{i}(b, v)}{\partial b}=(v-b) g_{j}(b)-\left[1+2 \theta_{i} k-\theta_{i}-k\right] G_{j}(b)+\theta_{i} k=0$.

Easy substitution and rearrangement give

$\phi_{j}^{\prime}(b)=\frac{\left[1+2 \theta_{i} k-\theta_{i}-k\right] F_{j}\left(\phi_{j(b)}\right)-\theta_{i} k}{(v-b) f_{j}\left(\phi_{j(b)}\right)}$.

Conducting the same computation for player $j$ can give us another ordinary differential equation (ODE) like Eq. (1). Then we can compute $\beta_{i}(v)$ as the inverse function of $\phi_{i}(b)$. On other intervals, the strategy becomes apparent, for the bidding functions are continuous and Assumptions 1 and 2 are restrictive. Specifically, $\beta_{i}(v)=\beta_{i}\left(\underline{w}_{i}\right)$ for $v \in\left[\underline{\mathrm{v}}_{i}, \underline{\mathrm{w}}_{i}\right]$, and $\beta_{i}(v)=\beta_{i}\left(\bar{w}_{i}\right)$ for $v \in\left[\bar{w}_{i}, \bar{v}_{i}\right]$.

\section{The uniform case}

In this section, we study the behavior of players with symmetric uniform distribution. We assume $v_{i} \sim U(0,1)$ for $i=1,2$, and get the bidding function of player $i$ on the interval $\left[\underline{w}_{i}, \bar{w}_{i}\right]$ with parameters $\theta_{i}$ and $k$, that is,

$\beta_{i}\left(v ; \theta_{i}, k\right)=\frac{v+\frac{1}{2} k\left(1+2 \theta_{i} k-k\right)}{2+2 \theta_{i} k-\theta_{i}-k}$.

Fig. 1 shows the bidding functions when $\theta_{1}=\frac{2}{3}$ and $k=\frac{1}{4}$. Actually, it can be easily shown from Eq. (2) that if only $\theta_{1} \geq \theta_{2}, \beta_{1}(v) \geq \beta_{2}(v)$, that is, the one with the larger share always bids more aggressively than her competitor. From now on, we let $\theta_{1} \geq \theta_{2}$, i.e., $\theta_{1} \geq \frac{1}{2}$ for convenience, and study the efficiency of $k+1$-bargaining by measuring the ex ante probability of inefficient allocations (IA). Tedious computation gives us

$\operatorname{Prob}(I A)=\frac{1}{2}-\frac{2-\theta_{1}+\left(\theta_{1}-\frac{1}{2}\right) k(1-k)}{2\left(1+\theta_{1}+k-2 \theta_{1} k\right)\left(2+2 \theta_{1} k-\theta_{1}-k\right)}$

Observe that if $\theta_{1}=\frac{1}{2}, \operatorname{Prob}(\mathrm{IA})=0$, and we have an efficient mechanism, no matter which value $k$ takes. This result is a special case in Cramton et al. (1987). If $\theta_{1} \neq \frac{1}{2}$, Prob(IA) $>0$. We compute the first order condition of an optimal $k$ as

$$
\frac{\partial \operatorname{Prob}(I A)}{\partial k}=\frac{\left[2-\theta_{1}+\left(\theta_{1}-\frac{1}{2}\right) k(1-k)\right]\left[\left(\theta_{1}-2\right)^{2}+2\left(\theta_{1}-\frac{1}{2}\right)^{2} k(1-k)\right]}{\left(1+\theta_{1}+k-2 \theta_{1} k\right)^{2}\left(2+2 \theta_{1} k-\theta_{1}-k\right)^{2}} .
$$

On the left of Eq. (3), the first two terms are both positive, and it is obvious that when $k<\frac{1}{2}$, $\operatorname{Prob}(\mathrm{IA})$ is decreasing in $k$, and that when $k>\frac{1}{2}$, Prob(IA) is increasing in $k$. So $k=\frac{1}{2}$ minimizes our measure of

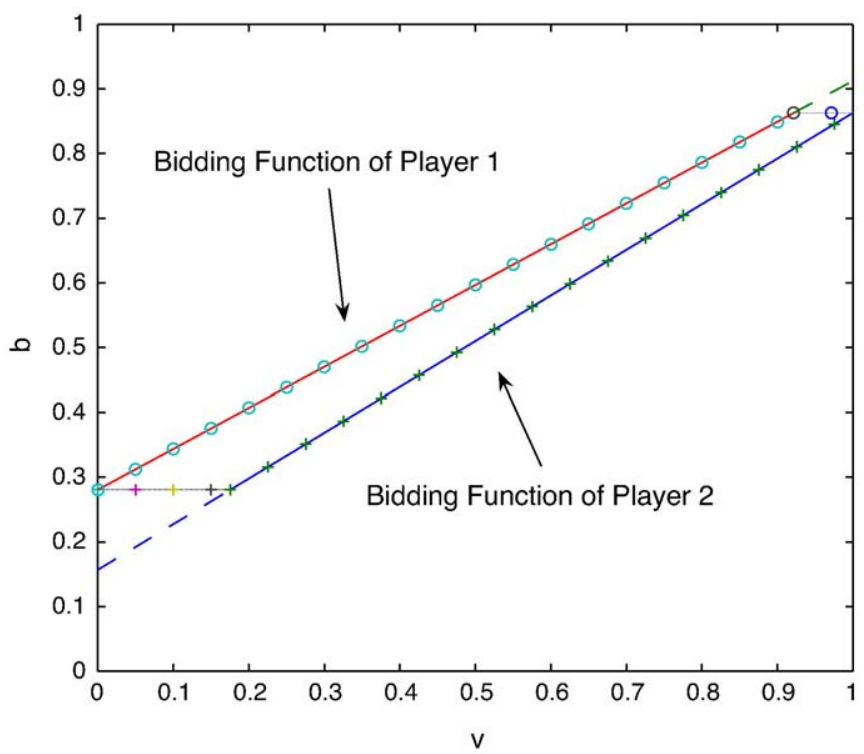

Fig. 1. Bidding functions. 
Table 1

Number of observations for each category. ${ }^{1}$

\begin{tabular}{llllll}
\hline \multirow{2}{*}{$\begin{array}{l}\text { Num of books } \\
\text { of player } 1\end{array}$} & \multicolumn{2}{l}{ First price } & & \multicolumn{2}{l}{ Second price } \\
\cline { 2 - 3 } \cline { 5 - 6 } & Player 1 & Player 2 & & Player 1 & Player 2 \\
\hline 4 & $\#(1)=0$ & $\#(2)=20$ & & $\#(3)=20$ & $\#(4)=0$ \\
2 & $\#(5)=10$ & $\#(6)=10$ & & $\#(7)=10$ & $\#(8)=10$ \\
3 & $\#(9)=20$ & $\#(10)=20$ & & $\#(11)=20$ & $\#(11)=20$ \\
\hline
\end{tabular}

1 Arguments of the \#() functions represent the category order.

inefficiency. This is consistent with previous seller-buyer bargaining models, for instance, in Chatterjee and Samuelson (1983). Myerson and Satterthwaite (1983) also show that in the symmetric uniform case, the split-the-difference bargaining $\left(k=\frac{1}{2}\right)$ is the optimal mechanism that maximizes expected total gains from trade when the object belongs to one of two players. Although first-price and second-price auctions are popular in practice, they generally make an efficient trade least possible.

\section{Experimental evidence}

\subsection{Experiment setup}

We conducted experiments for understanding the behavioral side of the model above. Our experiments were conducted at the University of Bonn. Participants were recruited from the campus canteen and had no previous training in economics or game theory. Each participant played only one game and had to make exactly one decision. The subject was told, that she owned $b\{0,1,2,3,4\}$ books of a 4 -volumed dictionary and she would interact with another player, who owned the remaining 4- $b$ books of the same dictionary. Each participant was informed about her private value $v$ for the whole dictionary, which was drawn from a uniform distribution from 0 to 10 Thalers. She was also informed, that the opponent private value followed the same uniform distribution. The participants were told that only, if she owned the complete dictionary she could realize this value $v$. The subject had to give an offer (sealed bid) how much she would like to pay for the 4 volumes. The payoff was calculated according to a firstprice (respectively second-price auction): if the amount the opponent was willing to pay was higher than the subject's bid, then the subject had to hand her volumes, and received a compensation of $b / 4$, of the opponent's bid in the case of the first-price auction (her bid in the case of second-price auction). In this case the subjects' payoff was the compensation she got from its opponent in Thalers. If the subject's bid was higher than the opponent's bid, her payoff was the value $v$ of the books minus the compensation she had to pay to her opponent. If both players bid the same price, the participant who got the complete dictionary would be drawn randomly with probability $1 / 2$, which never happened during the experiment. Each subject got 0.5 EURO show-up fee. The conversion rate was 0.5 EURO per Thaler. We summarize the observations taken in Table 1.

We did not test categories 1 and 4 , because rationally bidders would have just bid their own values, shedding little light on the validity of our theory. Owing to the symmetric distribution of books in some cases, we cut observations into half. Overall, we had 160 participants, 20 for each of the 8 tested types.

\subsection{Experiment result}

For each participant, we calculate the quadratic distances $\left(b_{i}-e_{(i, T)}\right)^{2}$ between her bid $b_{i}$ and the prediction $e_{(i, T)}$ of the theory $T$. The theory set includes 9 different bidding behaviors for 12 categories. For each of the 8 types observed, we test whether their bids follow the right bidding behaviors against alternative ones. Table 2 shows the results. Economics works!

First result: except for categories 2 and 3, our predictions are consistent enough to be better or no worse than alternatives in a statistical sense. There are only 4 players in category 2 bidding their own values, and only 1 bidding higher, implying that bad predictions in this categories are at large because players did not shed enough their bids from their values. For category 3 , the prediction is that these owners set reserve prices higher than their private values, and 14 of them did so, and 5 others bid their own value. We do not have plausible explanation for this phenomenon.

Second result: generally speaking, a theory for a first-price category can easily reject alternative predictions from a second-price category and vice versa. Moreover, the larger the book difference from the setting of the alternative theory to the right one, the easier the rejection, which is most evident for category 10 .

Third result: we are not able to legitimize the kinks like those in Fig. 1. Kinks show up in theoretical predictions for category 10 and 11 . With kinks, the mean squared distances are 1.45 and 4.21 respectively as in Table 1 , but if we allow the bidding functions to straighten up, the squared distances drop to 0.68 and 1.54 , sharp decreases if we take into account that the private values requiring kinks are exceptions rather than the rule. A tentative explanation is that the kinking behavior requires the players to reason that their opponents must not bid higher or lower than

Table 2

Test of fitness of prediction. ${ }^{2}$

\begin{tabular}{|c|c|c|c|c|c|c|c|c|c|c|c|c|c|}
\hline & \multirow[t]{2}{*}{ Category } & \multirow[t]{2}{*}{ Book } & \multirow[t]{2}{*}{$\mathrm{k}$} & \multirow{2}{*}{$\begin{array}{l}\text { Quadratic } \\
\text { distance }\end{array}$} & & \multicolumn{2}{|c|}{ First Price } & \multirow[b]{2}{*}{3 Books } & \multirow{2}{*}{$\begin{array}{c}\text { First } / 4 \\
\text { Second/0 }\end{array}$} & \multicolumn{3}{|c|}{ Second Price } & \\
\hline & & & & & 0 Book & 1 Book & 2 Books & & & 1 Book & 2 Books & 3 Books & 4 Books \\
\hline \multirow{4}{*}{ 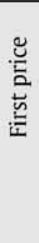 } & 2 & 0 & 0 & 4.23 & 4.23 & $\begin{array}{c}3.02 \\
-\end{array}$ & $\underset{\wedge}{1.74}$ & 0.69 & $\begin{array}{l}0.31 \\
\wedge \wedge \wedge\end{array}$ & $\begin{array}{c}5.49 \\
-\end{array}$ & $\underset{* *}{5.76}$ & $\underset{* * *}{9.20}$ & $\underset{* * *}{12.34}$ \\
\hline & 9 & 1 & 0 & 1.06 & $\begin{array}{c}1.73 \\
-\end{array}$ & 1.06 & $\begin{array}{c}0.69 \\
-\end{array}$ & $\begin{array}{c}0.81 \\
-\end{array}$ & $\begin{array}{c}4.10 \\
* *\end{array}$ & $\underset{* * *}{8.99}$ & $\underset{* * *}{11.05}$ & $\underset{* * *}{14.24}$ & $\begin{array}{c}17.00 \\
* * *\end{array}$ \\
\hline & $5 \& 6$ & 2 & 0 & 2.65 & $\begin{array}{c}4.80 \\
* *\end{array}$ & $\begin{array}{c}3.64 \\
-\end{array}$ & 2.65 & 1.71 & $\begin{array}{c}4.18 \\
-\end{array}$ & $\begin{array}{c}7.70 \\
* * *\end{array}$ & $\begin{array}{l}9.16 \\
* * *\end{array}$ & 11.86 & $\underset{* * *}{14.26}$ \\
\hline & 10 & 3 & 0 & 1.25 & $\underset{* * *}{4.42}$ & $\begin{array}{c}3.01 \\
* *\end{array}$ & $\begin{array}{c}1.63 \\
*\end{array}$ & 1.25 & $\begin{array}{c}1.39 \\
-\end{array}$ & $\underset{* * *}{6.41}$ & $\underset{* * *}{7.05}$ & $\begin{array}{c}10.09 \\
* * *\end{array}$ & $\begin{array}{c}12.79 \\
* * *\end{array}$ \\
\hline \multirow{4}{*}{ 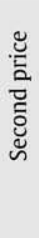 } & 11 & 1 & 1 & 4.21 & $\underset{* *}{10.29}$ & $\begin{array}{c}8.40 \\
* *\end{array}$ & $\begin{array}{c}6.24 \\
*\end{array}$ & $\begin{array}{c}4.93 \\
-\end{array}$ & $\begin{array}{c}2.01 \\
-\end{array}$ & 4.21 & $\begin{array}{c}3.38 \\
-\end{array}$ & $\begin{array}{c}5.75 \\
-\end{array}$ & $\begin{array}{c}8.10 \\
* *\end{array}$ \\
\hline & $7 \& 8$ & 2 & 1 & 1.80 & $\begin{array}{c}23.78 \\
* * *\end{array}$ & $\begin{array}{c}20.02 \\
* * *\end{array}$ & $\underset{* * *}{15.65}$ & $\underset{* * *}{14.43}$ & $\underset{*}{6.18}$ & $\begin{array}{c}2.28 \\
-\end{array}$ & 1.80 & $\begin{array}{c}1.69 \\
-\end{array}$ & $\begin{array}{c}1.94 \\
-\end{array}$ \\
\hline & 12 & 3 & 1 & 3.95 & ${ }_{* * *}^{15.05}$ & $\begin{array}{c}12.29 \\
* * *\end{array}$ & $\underset{* * *}{9.13}$ & $\begin{array}{c}8.27 \\
* *\end{array}$ & $\begin{array}{c}2.76 \\
-\end{array}$ & $\begin{array}{c}2.54 \\
-\end{array}$ & $\begin{array}{c}2.49 \\
-\end{array}$ & 3.95 & $\begin{array}{c}5.49 \\
-\end{array}$ \\
\hline & 3 & 4 & 1 & 6.30 & $\underset{*}{14.18}$ & $\underset{* *}{12.03}$ & $\begin{array}{c}9.59 \\
-\end{array}$ & $\begin{array}{c}7.90 \\
-\end{array}$ & $\underset{\wedge}{4.79}$ & $\begin{array}{c}3.12 \\
-\end{array}$ & $\begin{array}{c}3.48 \\
-\end{array}$ & $\begin{array}{c}4.81 \\
-\end{array}$ & 6.30 \\
\hline
\end{tabular}

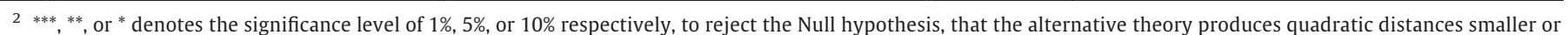
equal as those of our prediction with an one-sided Mann-Whitney $U$ test. ${ }^{\wedge \wedge}$, ${ }^{\wedge}$, , or ${ }^{\wedge}$ denotes the contrary. - denotes, that the tests yield no significant result. 
certain extreme values, which they often fail to do as recorded by numerous experiments involving several levels of second guessing.

\section{Discussion}

While the two-player scenario is the most common, $n$-person cases are also worth considering. More importantly, it is interesting if players with zero shares enter the mechanism. The Internet may facilitate combining complementary goods. A consumer holding one piece can submit the information to certain websites, and wait for someone with its complement. Our model suggests split-the-difference bargaining as an optimal mechanism, but there is an alternative-the open auction among share-holders and pure buyers.

\section{References}

Amann, E., Leininger, W., 1996. Asymmetric all-pay auctions with incomplete information: the two-player case. Games and Economic Behavior 14, 1-18.

Chatterjee, K., Samuelson, W., 1983. Bargaining under incomplete information. Operations Research 31 (5), 835-851.

Cramton, P., Gibbons, R., Klemperer, P., 1987. Dissolving a partnership efficiently. Econometrica 55, 615-632.

Lizzeri, A., Persico, N., 2000. Uniqueness and existence of in equilibrium with a reserve price. Games and Economics Behavior 30, 83-114.

Maskin, E., Riley, J., 2003. Uniqueness of equilibrium in sealed high-bid auctions. Games and Economic Behavior 45, 395-409.

Myerson, R.B., Satterthwaite, M., 1983. Efficient mechanisms for bilateral trading. Economic Theory 158, 265-281. 